\title{
EMERGENCIA TERRORISTA, SEGURIDAD, LIBERTAD. LA EXPERIENCIA ITALIANA ENTRE LA CONSTITUCIÓN Y LA LEGISLACIÓN (ESPECIALMENTE PENAL Y PROCESAL) ${ }^{1}$ TERRORIST EMERGENCY, SECURITY, FREEDOM. THE ITALIAN EXPERIENCE BETWEEN CONSTITUTION AND LEGISLATION (ESPECIALLY CRIMINAL AND PROCEDURAL)
}

\author{
SILVIO GAMBINO²
}

Recibido: 26/04/2019

Aceptado: 01/06/2019

\begin{abstract}
SUMARIO: I. INTRODUCCIÓN. II. CONCEPTO DE SEGURIDAD. III. LA SEGURIDAD COMO VALOR. IV. LA PONDERACION DE VALORES. V. NOTAS JURISPRUDENCIALES. VI. NOTAS LEGISLATIVAS. VII. LA NECESIDAD DE UNA LEGISLACIÓN ESPECIFICA. VIII. LA TENSIÓN ENTRE LIBERTAD Y SEGURIDAD. IX. LA PRIMERA LEGISLACION ITALIANA. X. LA CONSTITUCIONALIDAD DE DICHA REGULACIÓN. XI LAS MEDIDAS ADOPTADAS EN LOS AÑOS 70-90. XII. LA PRIMERA JURSIPRUDENCIA CONSTITUCIONAL. XIII. LA VIGENTE LEGISLACIÓN ANTITERRORISTA. XIV. CONCLUSIONES.
\end{abstract}

SUMMARY: I. INTRODUCTION. II. CONCEPT OF SECURITY. III. SECURITY AS A CONSTITUTIONAL VALUE. IV. CHEKS AND BALANCES BETWEEN VALUES. V. JURISPRUDENTIAL NOTES. VI. LEGISLATIVE NOTES. VII. THE NEED FOR A SPECIFIC LEGISLATION. VIII. THE TENSION BETWEEN FREEDOM AND SECURITY. IX. THE FIRST ITALIAN LEGISLATION. X. THE CONSTITUTIONALITY OF THIS REGULATION. XI THE MEASURES ADOPTED IN THE 70-90 YEARS. XII. THE FIRST CONSTITUTIONAL JURSIPRUDENCE. XIII. THE CURRENT ANTITERRORIST LEGISLATION. XIV. CONCLUSIONS

Resumen: Tras una reflexión introductoria sobre los estados de excepción y la salvaguardia de la seguridad y los derechos fundamentales en los sistemas constitucionales contemporáneos, el análisis se centra en la experiencia italiana en materia de legislación para la lucha contra el terrorismo ('negro' y 'rojo') y en la jurisprudencia constitucional en materia de legitimidad de este tipo de medidas para su represión. En este marco, se dedica una atención especial al análisis de la naturaleza de las situaciones jurídicas afectadas por estas políticas. El análisis del equilibrio y de los balances entre libertad y seguridad se enmarca en la perspectiva doctrinal y en la evolución de la jurisprudencia constitucional sobre el tema. Sobre todo, el análisis subraya la necesidad de reconsiderar la legislación penal y procesal, prestando la debida atención a la naturaleza específica de los delitos relacionados con el fundamentalismo religioso islámico y, en este contexto, a los problemas que presentan los niveles mínimos de anticipación de las sanciones penales para la prevención de esos actos delictivos, para que las políticas de contraataque sean eficaces, pero también respetuosas de los derechos fundamentales de las personas que son objeto de la investigación.

Palabras clave: Terrorismo, derechos fundamentales, sistema constitucional.

Abstract: After an introductory reflection on emergency situations and the safeguarding of security and fundamental rights in contemporary constitutional systems, the analysis focuses on the Italian experience with regard to counter-terrorism legislation ('black' and 'red') and on the constitutional jurisprudence concerning the legitimacy of this type of repressive measures. Within this framework, special attention is

\footnotetext{
1 Traducido del italiano por el dott. Claudio Di Maio, Universidad de Calabria, Italia.

2 Catedrático Derecho Constitucional Comparado de la Universidad de Calabria (Italia), silvio.gambino@unical.it.
} 
has been dedicated to the analysis of the legal situations affected by these policies. Examination of the equilibrium and balance between freedom and security is part of the doctrinal perspective and the evolution of constitutional jurisprudence on this topic. The study underlines the importance of reconsidering criminal and procedural legislation, giving due attention to the specific nature of crimes related to Islamic religious fundamentalism and, in this context, to the problems presented by the minimum levels of anticipation of penal punishments in order to prevent such criminal acts, so that counter-attack policies are effective, but also respectful of the fundamental rights of the persons under investigation.

Key words: Terrorism, fundamental rights, constitutional systems.

I. El paso del tiempo y la aparición de nuevas cuestiones relacionadas con la globalización de los intercambios económicos y sociales, ha producido que la dinámica de la relación entre libertad y seguridad ocupe un lugar cada vez más central (en la opinión pública y) en los estudios de derecho constitucional y comparado.

Los orígenes menos apreciables de la problemática que concierne a esta relación se remontan al período inmediatamente posterior a la implosión del bloque soviético (que también fue precedido simbólicamente, en 1989, por la caída del “Muro de Berlín”) y el final de la Guerra Fría. A partir de estos acontecimientos histórico-políticos, una inestabilidad internacional difusa y un conjunto de conflictos han atravesado (y siguen atravesando) muchas regiones del planeta, acompañados de la creación de formas agresivas de terrorismo inspiradas en el fundamentalismo religioso de matriz islámica. En algunos países europeos, recientemente, la violencia de tales manifestaciones nos ha hecho olvidar (casi) el miedo y la sensación de inseguridad producida por el terrorismo ideológico y la violencia -no menos agresiva y alarmante en su momento- llevada hasta el "corazón del Estado" (como se afirmaba en los documentos delirantes de la derecha y de la izquierda de la época).

La revivificación del terrorismo en los primeros años del nuevo milenio, a partir de los trágicos y odiosos atentados de Nueva York (del once de septiembre de 2001), seguidos de los igualmente traumáticos atentados que han ensangrentado Madrid, Copenhague, París y Bruselas, ha agravado aún más este panorama, complicando (aunque en muchos sentidos incluso aleatoriamente) la estrategia institucional de lucha contra el terrorismo, ya que los Estados democráticos no pueden contrarrestarlo renunciando a la legalidad y, de forma más general, al respeto de los principios del Estado de Derecho.

Como señaló el Tribunal de Estrasburgo (de forma convincente) en la sentencia Trabelsi ( $\mathrm{n}^{\circ}$ 50163/08), "la fuerza de la democracia se mide precisamente cuando, incluso en presencia de un peligro inminente, se sigue actuando de acuerdo con la ley" ${ }^{3}$. Este enfoque jurisprudencial, alimentado por las sucesivas y reiteradas sentencias que condenan a Italia por infracción del artículo 2, apartado 1, letras a) y b) y 3 del CEDH, así como del Reglamento (CEE) $n^{0}$ 1408/71, fue adoptado por el Tribunal de Primera Instancia de las Comunidades Europeas, , ha sido confirmado por el juez de Estrasburgo respecto a la prohibición de expulsión, traslado o extradición de acusados (independientemente de su nacionalidad) y condenados a países en los que se prevé la pena de muerte y se recurre a la tortura o a los tratos inhumanos y degradantes; prohibición que debe considerarse absoluta, incluso en situaciones de emergencia terrorista ${ }^{4}$. El Tribunal Supremo de Casación italiano ha cumplido esta orientación

\footnotetext{
${ }^{3}$ C. Vigilanti, "I diritti dei terroristi. (Il caso Trabelsi: un difficile equilibrio fra esigenze di pubblica sicurezza e garanzie dei diritti fondamentali)", en www.forumcostituzionale, 2010.

${ }^{4}$ Gran Sala, sentencia de 28 de febrero de 2008, № 37201/06, Saadi c. Italia.
} 
jurisprudencial, adoptando la lectura según la cual "los derechos humanos fundamentales no pueden ser objeto de evaluación con ningún otro interés público, aunque sea el de la seguridad de los Estados nacionales, por lo que no existe ningún margen de discrecionalidad por parte de las administraciones públicas, que deben evaluar la solicitud de asilo por parte del extranjero" 5 .

En este marco y con el fin de luchar contra el terrorismo, se han previsto medidas preventivas y represivas de este fenómeno criminal -desde hace más de treinta años- en la totalidad de los países de democracia pluralista (a ambos lados del océano), caracterizando así toda la estructura de la democracia contemporánea.

Con respecto a estas medidas y al riesgo inherente de una clara separación entre los requisitos de seguridad y la cultura de la legalidad -además del cumplimiento de la Constitución de la "legislación de emergencia terrorista"-, la ciencia constitucional ha cuestionado la misma necesidad y conformidad constitucional de una "Constitución de emergencia" ${ }^{6}$, que elabora principios y normas adecuadas para "salvaguardar la libertad y los derechos civiles frente al peligro del terrorismo", asegurando a los Ejecutivos el ejercicio de la garantía de seguridad sin causar daños duraderos a los derechos individuales y, en todo caso, sin traspasar, en esta lucha contra el terrorismo, los límites impuestos por la “decencia”.

II. Antes de entrar en el análisis de la "legislación de emergencia” adoptada por el legislador italiano en las dos grandes épocas de la "lucha contra el terrorismo", tanto nacional como internacional, conviene detenerse, previamente, en recordar un tema fundamental que figura ahora en el orden del día del debate teórico de los estudios constitucionales y comparados, es decir, de las relaciones (a menudo inciertas y problemáticas y que siguen siendo dogmáticamente abiertas) entre los objetivos y los límites sancionados en las democracias (modernas y contemporáneas), la persecución penal y el enjuiciamiento de la lucha contra el terrorismo (y en el ordenamiento jurídico italiano también de la delincuencia organizada) y las limitaciones jurídicas impuestas por el constitucionalismo contemporáneo en un sistema con una Constitución rígida (reserva de ley y reserva de jurisdicción).

El conjunto de estas relaciones tiene que ser profundizado prestando especial atención al equilibrio de las garantías constitucionales entre libertad y seguridad, con la búsqueda, dentro de ellas, de una ponderación más adecuada "en sede política antes que judicial" ${ }^{7}$ ).

En este equilibrio, es necesario valorar todas las exigencias (teóricas y prácticas) que plantean la necesaria "desconfianza hacia la obsesión por la seguridad"8, pero, al mismo tiempo, captar las consecuencias dinámicas de la evolución de la forma del Estado, en el constitucionalismo contemporáneo, con respecto a las garantías que proceden de los principios liberal-democráticos y en tal marco del derecho a la seguridad, en sus diferentes declinaciones constitucionales.

Estas modulaciones se refieren al concepto de la seguridad en sus distintos perfiles: en sentido estricto, como “orden público y seguridad” y, en una concepción más

\footnotetext{
5 Corte di Cassazione, Sez. Un. Civile, ordinanza n. 19393, 9 de septiembre de 2009.

6 B. Ackerman, La Costituzione di emergenza. Come salvaguardare libertà e diritti civili di fronte al pericolo del terorrismo, Roma, 2005.

7 L. Stortoni, “Diritti dell’uomo ed emergenza: (l'eredità de) gli anni di piombo”, en Critica del diritto, 1997, 1, 61 ss.

8 L. Wurtz, “Obsessions sécuritaires”, en Le Monde diplomatique, octubre 2003.
} 
amplia y dinámica (funcional a la misma protección de los derechos sociales), como interés de la comunidad, adecuada para equilibrar los derechos de libertad en función de la "vida civil ordenada" .

Es en relación con este último perfil que, en la dinámica de los equilibrios entre seguridad y libertad (tanto antiguos como nuevos), la seguridad debe analizarse en su naturaleza más profunda, tanto como concepto dinámico que, como situación jurídica específica, para evitar que, en el equilibrio que los dos bienes jurídicos hacen los legisladores, pero sobre todo los jueces constitucionales, se puedan oscurecer las más profundas "relaciones entre seguridad, libertad y solidaridad" 10 .

En cuanto a la naturaleza y variabilidad de las situaciones jurídicas garantizadas constitucionalmente, la evolución del constitucionalismo liberal hacia el constitucionalismo social contemporáneo, como es bien sabido, describe una profunda transformación tanto de la concepción (y de la eficacia) de los derechos fundamentales como de la misión misma del Estado y, con ella, de la totalidad de sus objetivos.

La disposición del principio constitucional de igualdad sustancial y la colocación de un complejo articulado de derechos sociales sancionan la transformación (teórica y constitucional) de las tareas del Estado hacia la persona (sobre todo del sujeto más débil), lo que conduce a la afirmación de un modelo completo de Estado de bienestar. Este modelo se denomina también "Estado de prevención”, cuya "tarea no es tanto (o mejor dicho, no es sólo) garantizar el derecho a la seguridad personal de las personas individuales, sino la seguridad global de los derechos de los ciudadanos y de los bienes jurídicos que los sustentan en un contexto social complejo y rico en contradicciones" ${ }^{11}$.

En la fase contemporánea de la evolución del Estado (multiclase y social), esta última situación jurídica (seguridad) puede ser mejor comprendida -por lo tanto menos alejada de las necesidades que plantea la protección del bien constitucional de la libertad personal- si se enmarca en una lectura doctrinal convincente (centrada en la búsqueda de la "otra cara de la seguridad” (M. Ruotolo), que la concibe como "certeza del derecho", como "seguridad en el derecho" 12 , superando así el enfoque estático (seguridad y orden público) inherente a la lectura del siglo XIX del instituto en favor del fortalecimiento de la asunción promocional del concepto de seguridad como reivindicación constitucionalmente garantizada de los sujetos frente a los poderes públicos, con el fin de lograr la eliminación de los obstáculos que se interponen al goce efectivo de los derechos y, con ello, la realización de la "libertad de la necesidad".

III. En el marco de las respuestas que la doctrina constitucional ha ofrecido respecto a las torsiones legales provocadas por el terrorismo, la seguridad, según ciertas orientaciones (ya citadas) orientadas a la previsión de una derogación constitucional (temporal) frente a (y para superar) las situaciones de emergencia terrorista, parece elevarse al rango de "nuevo" valor constitucional ${ }^{13}$.

\footnotetext{
9 M. Ruotolo, “La sicurezza nel gioco del bilanciamento”, en G. Cocco (a cura di), I diversi volti della sicurezza, Milano, 2012, 18 ss.

10 P. Ceri, La società vulnerabile. Quale sicurezza, quale libertà, Roma-Bari, 2003, 45.

11 T.F. Giupponi, “Sicurezza personale, sicurezza collettiva e misure di prevenzione ... cit., 21 ss.

12 G. Peces-Barba, Teoria dei diritti fondamentali, Milano, 1993, 223 ss.

13 G. De Vergottini, "La difficile convivenza tra libertà e sicurezza: la risposta delle democrazie al terrorismo. Gli ordinamenti occidentali”, en AA.VV. (A.I.C.), Annuario 2003. Libertà e sicurezza nelle democrazie contemporanee, Padova, 2003; T.E. Frosini, "Il diritto costituzionale alla sicurezza", en www.forumdiquadernicostituzionali.it.
} 
En cuanto a las posibles reacciones de la población afectada por atentados terroristas graves y repetidos, que puedan inducir también el riesgo de ruptura del orden público y de la propia democracia, la doctrina citada sugiere incluir en el texto constitucional una cláusula destinada a regular los estados de emergencia terrorista, a través de la previsión de una "Constitución para el estado de emergencia” que permita la adopción de medidas operativas efectivas para evitar un segundo atentado a corto plazo, pero que, a la vez, establezca con firmeza un límite a la duración de las mismas” ${ }^{14}$. No es casualidad que el ensayo en el que se hace explícita tal orientación se rúbrica precisamente “Antes del próximo ataque" ${ }^{15}$, preocupando al erudito extranjero a especificar que, además de los complejos (y garantes) límites procedimentales previstos en la derogación de la revisión del texto constitucional, la cláusula de emergencia debe ocuparse de regular la naturaleza temporal del 'estado de emergencia', evitando la posibilidad de autorizar limitaciones duraderas de los derechos fundamentales.

Desde este punto de vista, hace tiempo, la disciplina de la seguridad ha sido objeto de medidas legislativas y de equilibrio judicial en las salvaguardias relativas (tanto de la libertad como de la seguridad), aunque no faltan directrices doctrinales críticas y directrices jurisprudenciales que siguen siendo inciertas o incluso contradictorias, sobre todo en la doctrina penal-procesalista y en una parte de la doctrina constitucional más crítica.

IV. Volviendo al tema central de nuestra intervención, cabe señalar que los sistemas constitucionales contemporáneos ponen de manifiesto una tensión considerable (aún no resuelta a nivel teórico y de derecho positivo) en la búsqueda de los equilibrios necesarios entre los dos bienes jurídicos mencionados, igualmente fundamentales -la protección de la libertad personal y (la de su convivencia con) el derecho a la seguridad.

La doctrina constitucional más atenta se ha movido en esta dirección durante algún tiempo, aunque en este momento -como ya se ha observado anteriormente- no tiene ningún resultado apreciable en la orientación de la disciplina legislativa. El derecho a la seguridad, en particular, se lee cada vez menos desde el punto de vista de la teoría de Hobbes que se remonta a la fundación del poder, valorando, más bien, aquellas garantías que fueron posteriormente aceptadas en las disposiciones del Art. 2 de la Déclaration des droits de l'home et du citoyen, que lo colocó entre los derechos (naturales e) inalienables del hombre ${ }^{16}$.

Frente a las transformaciones de los contextos nacionales e internacionales - (si no realmente promovidas al menos) determinadas por los procesos de globalización de la economía, por los intentos de controlar y regular los (escasos) recursos del planeta (especialmente la energía y el agua), así como los propios flujos migratorios masivos (y especialmente entre los solicitantes de asilo), y ante la aparición de una amenaza terrorista cada vez más extendida y agresiva, la seguridad se caracteriza tanto por ser una garantía de la continuidad del Estado y de sus funciones de protección de la paz social, como por ser un bien jurídico inseparablemente vinculado a la persona, al bien de la vida y a su dignidad.

Junto al marco tradicional y a las garantías constitucionales relativas a las libertades personales, transferidas al Estado para asegurar la superación del bellum

\footnotetext{
14 B. Ackerman, La Costituzione di emergenza ... cit., 175.

15 Ibidem.

16 T.E. Frosini, "Il diritto costituzionale alla sicurezza”, in www.forumdiquadernicostituzionali.it.
} 
omnium contra omnes, persiguiendo así el objetivo de la paz social, en la evolución más reciente del constitucionalismo occidental encontramos nuevas garantías entre las que además de un rico sistema de derechos fundamentales garantizados constitucionalmentese encuentra el derecho a la seguridad, entendido como un bien jurídico autónomo (como "seguridad de"), como un derecho fundamental de la persona, objeto, dentro de la jurisdicción constitucional, de equilibrios significativos con las garantías otorgadas a las libertades personales. Desde este punto de vista, se subraya que la seguridad, como derecho de la persona, debe "ir acompañada de las libertades de la persona y, por tanto, concebirse como un objetivo al que debe tender la acción del Estado y de los demás poderes públicos, siempre respetando plenamente el núcleo esencial de los demás derechos garantizados por la Constitución” ${ }^{17}$.

V. La jurisprudencia de los Tribunales Supremos en materia de legitimidad de las medidas de lucha contra el terrorismo, en épocas más recientes, ha escrito páginas importantes sobre el tema. A modo de ejemplo, nos referimos en este contexto a algunos pasajes del argumento del juez supremo israelí en relación con un caso de interrogatorio violento de un sospechoso de terrorismo ${ }^{18}$.

Estos argumentos son tanto más apropiados para la reconstrucción teórica de los pilares de la democracia en tiempos de guerra; subrayan, por ejemplo, que "somos conscientes de que esta decisión no hará más fácil enfrentarse a la realidad del terrorismo. Pero este es el destino de la democracia, porque no todos los medios son aceptables y no todos los métodos utilizados por sus enemigos son utilizables. A veces, una democracia tiene que luchar con una mano atada a la espalda. Preservar el papel de la ley y reconocer las libertades individuales es un componente importante de la definición de seguridad en una democracia” 19 .

Como bien se señala en el siguiente argumento, para Barak el terrorismo crea una gran tensión entre los componentes esenciales de la democracia: "Un pilar de la democracia -el gobierno del pueblo a través de sus representantes electos- puede fomentar que se tomen todas las medidas eficaces para combatir el terrorismo aunque sean perjudiciales para los derechos humanos. El otro pilar de la democracia -los derechos humanos- puede fomentar la protección de los derechos de todas las personas, incluidos los terroristas, incluso a costa de debilitar la lucha contra el terrorismo. Abordar esta tensión es la principal tarea de los poderes legislativo y ejecutivo, que deben rendir cuentas al pueblo" ${ }^{20}$. Pero la verdadera responsabilidad democrática no puede satisfacerse sólo con el juicio del pueblo: incluso el poder legislativo debe justificar sus decisiones ante los jueces responsables de proteger los principios de la democracia.

Por otro lado, como continúa Barak de manera argumentada, "los errores del poder judicial, cuando cesa la amenaza del terrorismo, permanecen en la democracia y están arraigados en la jurisprudencia de la Corte, como un imán para el desarrollo de nuevas y problemáticas leyes. Esto no sucede con un error del poder legislativo o

\footnotetext{
17 T.E. Frosini, "Il diritto costituzionale alla ..., 2.

18 M.Patrono, I diritti dell'uomo nel paese d'Europa. Conquiste e nuove minacce nel passaggio da un millennio all'altro, Padova, 2000.

19 A. Barak, "The Supreme Court and the Problem of Terrorism", in Judgements of the Israel Supreme Court; Fighting Terrorism within the Law, Gerusalemme, Institute for Legislative Research and Comparative Law, 2005.

20 A. Barak, "The Supreme Court and the Problem ... cit.
} 
ejecutivo que puede ser anulado por medio de leyes y acciones apropiadas y generalmente olvidado" ${ }^{21}$. La independencia e imparcialidad de los propios jueces se verían afectadas ${ }^{22}$.

VI. En cuanto a la regulación legislativa de la emergencia (y a las mismas posibles medidas de regulación constitucional), un enfoque similar de tipo introductorio a lo que se dirá, en relación con la experiencia italiana en materia de legislación para combatir el terrorismo y del relativo examen por la jurisprudencia constitucional, impone también la observación -desde la perspectiva interna del sistema italiano- de que las medidas previstas en la Constitución para hacer frente a situaciones de emergencia (tanto internacionales como internas) -en el peculiar carácter híbrido que las caracterizaparecen completamente ambiguas, ya que se combaten entre la definición de los problemas y la definición de las medidas constitucionales de disciplina de la guerra (arts. 78, 60.2, 27.4 Cost. italiana), por un lado, la necesidad (en la actualidad, como mera reflexión teórica en la perspectiva de jure condendo) de medidas derogatorias (temporales) de la Constitución previamente definidas con casos tipificados aptos para la lucha contra el terrorismo, por otro lado, y una legislación (de tipo aluvión) de medidas de lucha legal contra el terrorismo (y, a partir de cierto momento, integrando medidas de lucha contra la mafia y las demás asociaciones de delincuencia organizada) en relación con el derecho penal, el del juicio y, por último, el del ordenamiento penal (del orden penitenciario) ${ }^{23}$.

Desde este punto de vista específico, más recientemente, una parte de la doctrina ha observado que la emergencia terrorista interna e internacional -que había requerido medidas constitucionales de contraste en todo el constitucionalismo liberal-democráticose presenta ahora con características tales como no permitir que se siga utilizando la estructura ordinaria de las competencias constitucionales, al tiempo que se excluye que medidas derogatorias similares de la Constitución puedan afectar a la garantía de los derechos por un tiempo indeterminado ${ }^{24}$.

En cuanto a los Estados (incluido el italiano), la experiencia de los últimos veinte años demuestra que no se puede luchar contra los atentados terroristas recurriendo a medios (sólo) militares - recurriendo a la disciplina constitucional sobre la guerra-, siendo necesario un complejo y articulado conjunto de medidas legales, tanto de tipo preventivo (con el fortalecimiento de las funciones de recopilación e interpretación de información por parte de los sistemas de inteligencia) como represivo (con la predisposición de una legislación específica y a través de intervenciones de la organización administrativa y judicial), ambos idóneos para permitir el contraste y la neutralización de la actividad ilegal de las organizaciones terroristas y de comportamientos singulares de relevancia delictiva. Como diremos más adelante, la misma estrategia criminal de contrastar el terrorismo parece incongruente frente a la naturaleza específica de los atentados terroristas perpetrados por terroristas individuales inspirados en el fundamentalismo religioso de la matriz islámica y en la lealtad al autoproclamado Estado islámico.

\footnotetext{
21 A. Barak, "The Supreme Court and the Problem ... cit., 9-10.

22 A. Barak, "The Supreme Court and the Problem ... cit., 9-10.

23 P. Bonetti, “Terorrismo e stranieri nel diritto italiano. Disciplina legislativa e profili costituzionali”, en Diritto, immigrazione e cittadinanza, 2005, fasc. 3, 13-41.

24 P. Bonetti, “Terorrismo e stranieri ... cit., fasc. 3, 13-41.
} 
En la legislación más reciente -de conformidad con las directivas europeas específicas en materia de lucha contra el terrorismo- a estas medidas se añaden otras nuevas inspiradas en la prevención a través del recurso a las interceptaciones telefónicas y a la localización de las huellas informáticas y telemáticas de los sistemas telefónicos y telemáticos con el fin, como se verá más adelante, de anticiparse a la comisión del hecho ilícito en lugar de limitarse a su única represión penal, excepto para establecer el umbral en el que se deben colocar las medidas de prevención para resultar respetuosas con los principios constitucionales.

Como otras emergencias, de hecho, el sistema terrorista requiere que el sistema estatal se encargue de proporcionar medidas adecuadas de lucha en la legislación (constitucional y legislativa), así como en la gestión del orden público y la seguridad. Tal respuesta -como ya se ha observado- debe consistir no sólo en una lucha adecuada por parte de las fuerzas de seguridad pública en el momento en que se producen los acontecimientos, sino también en su prevención mediante sistemas administrativos de inteligencia convenientemente coordinados a nivel europeo y a nivel interno. La activación del Fiscal Europeo (prevista en el artículo 86 del Tratado de Lisboa) sería una respuesta institucional muy adecuada a este respecto.

El reciente debate iniciado en el marco de las instituciones europeas ${ }^{25}$ constituye una oportunidad indispensable para que las instituciones europeas pongan remedio a la inercia de la que se quejan diversas partes (tanto en la doctrina como en la opinión pública europea) y que ha tenido su respuesta más trágica en la falta de coordinación entre las fuerzas policiales de países limítrofes como Francia y Bélgica con motivo de los recientes atentados terroristas perpetrados en los dos países por grupos armados fundamentalistas que se referían al Estado islámico. La recurrente propensión de los nuevos terroristas a utilizar el suicidio para producir masacres y la alarma colectiva imponen, desde este punto de vista, como ya se ha observado, una profunda revisión de las políticas criminales seguidas hasta ahora para combatir el terrorismo.

VII. A partir de la reflexión introductoria sobre el tema de las relaciones entre los estados de excepción, la salvaguardia de la seguridad y de los derechos fundamentales, se ha subrayado que en la mayoría de los sistemas de democracia pluralista faltan regulaciones normativas adecuadas para hacer frente a las situaciones de emergencia, si se ignora la declaración del "estado de guerra" prevista, aunque con diferente intensidad, en las constituciones contemporáneas y, naturalmente, si se hace una excepción para la disciplina de los “plenos poderes”, limitada a la experiencia constitucional francesa (Art. 16).

Esta regulación se aplica en casos excepcionales, en el entendimiento de que conviene distinguir la transición del estado de paz al estado de guerra, teniendo en cuenta que pueden darse una serie muy variada de casos intermedios que son relevantes desde el punto de vista penal. En cualquier caso, la importante diferenciación entre los dos regímenes jurídicos de la guerra y el estado de emergencia es bastante clara.

En este contexto, el delito penal de terrorismo, especialmente en su versión actual, no parece ser un fenómeno que pueda ser abordado por medios militares, ya que implica la acción del sistema jurídico tanto dentro como fuera de él. Mientras tanto, este

\footnotetext{
25 J. Lozano Miralles, “Seguridad Común e Integración Europea en la lucha contra el Terrorismo en la Unión Europea”, en Federalismi.it, n. 1/2019, pp. 71 y ss.
} 
fenómeno se refiere a la protección internacional y europea otorgada sobre la base de las respectivas Cartas, es necesario -en cuanto a los perfiles internos- una legislación precisa dirigida a prevenir la presencia y la actividad terrorista (que, a veces, está connotada con acciones discontinuas, de agresión masiva o sólo colectiva) y con intermitencia entre la acción terrorista en sentido estricto y las meras amenazas de atentados terroristas.

Se ha observado que -por la doctrina constitucional más atenta- las mismas constituciones deben prever medidas adecuadas de lucha para enfrentar tales estados de emergencia, apoyando positiva y constitucionalmente los equilibrios necesarios en favor de las libertades personales y, al mismo tiempo, de la seguridad, que constituye -en sí misma, como se ha observado anteriormente- una de las expresiones contemporáneas de la libertad, aunque en la modulación que se le ha dado, en el pasado, en el momento de subrayar sus perfiles pretenciosos hacia conductas que promuevan la libertad y la igualdad de todos los sujetos.

En este contexto, una vez que se recuerda que es la Carta Fundamental la que está en el origen del orden constitucional y de la estructura de los poderes relativos y de las relaciones entre los mismos y los ciudadanos (pero más en general los sujetos), es la misma ley interna -más que el legislador ordinario- la que parece tener que regular la disciplina de los regímenes jurídicos ex ante con respecto a los que se establecen como consecuencia de la aparición de situaciones de emergencia.

De esta manera, el riesgo de que la medida de emergencia pueda degenerar se reduce sobre la base de la disposición constitucional expresa (además de los necesarios controles parlamentarios y judiciales correspondientes). Una tesis -la segunda- que se refiere a esa doctrina (citada) en el extranjero que (aunque desde una perspectiva de jure condendo) subraya la necesidad, en el contexto de las democracias contemporáneas, de una "Constitución de emergencia”, con formas adecuadas de control político y parlamentario sobre la disposición constitucional de los recursos preventivos.

En cuanto a los regímenes constitucionales derogatorios, sin embargo, se plantean muchos problemas de encuadramiento teórico y de derecho positivo, ya que en la reflexión teórico-constitucional destaca el mismo debate sobre los plenos poderes en el orden constitucional francés y sobre la llamada "democracia comisaria"26. Cuando no están previstas en el texto escrito, las mismas se justifican sobre la base del principio de conservación, inherente a todo sistema. Su carácter problemático se relaciona con la discrecionalidad normativa utilizada para hacer frente a la emergencia que ha surgido $\mathrm{y}$, en última instancia, con la consideración de que determina la transferencia de poder para decidir en la crisis y sobre la crisis del Parlamento al Ejecutivo.

Así, en general, los regímenes de excepción, tanto cuando están predeterminados en la Constitución como cuando no lo están, pueden calificarse como "regímenes que se apartan de la normalidad y se caracterizan por su temporalidad... Su introducción implica la suspensión de la parte de la Constitución con la que están en contradicción, y desde un punto de vista lógico es la suspensión de la eficacia de las normas constitucionales", que permanecen inactivos para volver a ser plenamente aplicables cuando dejan de cumplirse las condiciones para la suspensión, lo que permite la introducción del régimen derogatorio, que constituye una excepción a la norma constitucional y que con frecuencia se califica de excepcional” 27.

\footnotetext{
26 M. Volpi, La democrazia autoritaria, Bologna, 1979.

27 G. De Vergottini, “La difficile convivenza tra libertà e sicurezza ... cit., p. 55 ss.
} 
VIII. En cuanto al problema de la seguridad en el marco más amplio de las dudas e incertidumbres de la teoría constitucional, pero también de los requisitos concretos de continuidad de los sistemas, este problema es un derecho real que debe ser garantizado, tanto interna como externamente. A su vez, la guerra en ciertas estrategias de defensa contra los ataques terroristas (como la guerra norteamericana contra los llamados "Estados delincuentes") ya no se considera sólo como una medida de defensa, sino que se ha convertido en una medida preventiva, alcanzable incluso en ausencia de un ataque concreto.

La lógica de esta orientación teórica responde también a la necesidad de evitar el debilitamiento de las instituciones públicas como consecuencia de la emergencia, por lo que en esta perspectiva la ley pretende establecer un equilibrio entre la necesidad de seguridad del ciudadano y la protección de la libertad de la persona. Desde este punto de vista, como argumentan las jurisdicciones constitucionales, el Estado de derecho parece actualmente asignable a los requisitos de salvaguardia de la seguridad, en la medida en que la razón (moderna) del Estado y la teoría de la necesidad son "redescubiertas" como legitimadoras de la introducción de regímenes derogatorios.

Lo que parece particularmente problemático, analizando el panorama que ha surgido especialmente en los últimos veinte años, es que los sistemas jurídicos no han proclamado ningún "estado de emergencia”, adoptando medidas para hacer frente a las nuevas situaciones críticas que han surgido a través del uso de la legislación ordinaria. Esto significa que las medidas que deben ser de naturaleza específica son de hecho casi indefinidas. La normalización de las emergencias implica el uso de fuentes ordinarias y, en particular, de la ley en todos los sistemas jurídicos, incluidos los que han previsto en su constitución regímenes jurídicos que establecen excepciones a los derechos en relación con la gestión de emergencias.

Si analizamos las situaciones de emergencia nacional y las respuestas dadas por los legisladores (y entre ellos por el italiano), podemos decir que, en general, los nuevos estados de emergencia han conducido, por regla general, a un debilitamiento general y peligroso de los derechos a la libertad. El derecho de asociación y la protección de la vida privada en estos casos representan los ejemplos límite en cuanto a la limitación relativa ${ }^{28}$.

La "guerra contra el terrorismo", de esta manera, registra una evidente y problemática prevalencia de la protección de la seguridad por encima de la libertad, sobre todo tras los atentados terroristas de Nueva York y las reacciones legales registradas en Estados Unidos ${ }^{29}$, pudiendo extraer de ella "la impresión general .... de que, mientras la situación internacional de conflicto o de grave tensión siga con riesgos evidentes de su repercusión interna, la legislación que limita los derechos constitucionales está destinada a volverse crónica y que, en consecuencia, la garantía de los principios del Estado de Derecho acabará concentrándose en la coherencia y eficacia de los controles encomendados a las jurisdicciones, así como en los controles que, a otro nivel, pueden ejercer las representaciones políticas parlamentarias”30.

Con la nueva situación de emergencia, marcada por los trágicos acontecimientos del 11 de septiembre (y por lo que ha seguido, también por los límites

\footnotetext{
28 F. Pizzetti, “Lotta al terrorismo e tutela della privacy”, in AA.VV., Lotta al terrorismo e tutela dei diritti costituzionali, Torino, 2009.

29 S. Gambino, A. Scerbo, “Diritti fondamentali ed emergenza nel costituzionalismo contemporaneo. Un'analisi comparata”, en Rivista di Diritto Pubblico Comparato ed Europeo, n. 4/2009; T.E. Frosini, C. Bassu, La libertà personale nell'emergenza costituzionale, en A. Di Giovine (cur.), Democrazie protette e protezione della democrazia, Torino, Giappichelli, 2005.

30 G. De Vergottini, “La difficile convivenza tra libertà e sicurezza ... cit., p. 55 ss.
} 
evidentes registrados en las estrategias geopolíticas, especialmente en los contextos de los países del Norte de África y del Oriente Próximo y en los llamados "manantiales árabes”), la teoría y el derecho constitucional se enfrentan de esta manera a otra frontera que se suma a los problemas clásicos planteados por el dualismo entre autoridad y libertad.

Los derechos fundamentales deben enfrentarse ahora de forma más concreta con otro derecho fundamental, el de la seguridad, que todo sistema, pero sobre todo los ciudadanos de los Estados occidentales, asumen como esencial y, por tanto, imperativo. Por lo tanto, puesto que las necesidades de seguridad han aumentado considerablemente en comparación con el pasado, los derechos de libertad -por varias razones- se ponen en tensión con ellos, con la posibilidad y el riesgo no abstracto de su compresión indebida, ya que, como ocurre en la práctica, al menos en la fase inmediatamente próxima a los graves atentados terroristas y a los temores y ansiedades que provocan, se dispone que el cuerpo social solicite y acepte limitaciones de las libertades funcionales a las necesidades de la seguridad.

Ahora se puede hacer una consideración final con respecto a la seguridad. El enfoque del tema que el jurista, de hecho, está llamado a afrontar tiene por objeto subrayar la necesidad de evitar que el bien constitucional de la seguridad se dilate excesivamente, en virtud del temor que la amenaza terrorista, como se acaba de observar, puede ejercer sobre la opinión pública en el ámbito de las sociedades actuales. Esta cuestión parece tener una importancia capital, ya que las posibles involuciones y regresiones autoritarias de los sistemas jurídicos pueden verse favorecidas por la falta de conocimiento público de los bienes realmente en juego. Sobre la base de esta premisa, sería ciertamente útil (pero que no podemos hacer ahora por razones de economía del presente artículo) poder profundizar la experiencia americana en relación con las cuestiones mencionadas anteriormente ${ }^{31}$.

Las recientes manifestaciones del terrorismo, debido a las numerosas posibilidades de atentados (aviones, gases venenosos, etc.) y a los nuevos y cada vez más accesibles medios de comunicación, imponen a los sistemas jurídicos una nueva forma de hacer frente a la emergencia, que dista mucho de ser atribuible a los clásicos instrumentos represivos del derecho penal. Por estas razones, los estados de excepción deben incluirse dentro de un umbral más allá del cual no pueden rebasar, en lo que respecta a la protección de las libertades civiles. Es por esta razón, en particular, que los poderes de emergencia no deben poder buscar su legitimidad sobre la base del pánico colectivo, sino que deben basarse en disciplinas positivas adecuadas para hacerse cargo de la protección de los bienes de rango constitucional, a fin de no eludir los mecanismos de contrapeso político y jurídico. Desde este punto de vista, la `guerra contra el terrorismo', expresión técnica utilizada habitualmente después del 11 de septiembre, no puede sino considerarse impropia, lo que no resulta en "un concepto jurídico convincente" 32 .

En conclusión, sobre este punto, puede subrayarse que la "guerra contra el terrorismo” (a menudo subrayada enfáticamente por los Jefes de Estado preocupados por los atentados terroristas), si, por una parte, constituye una necesidad jurídica y política

\footnotetext{
31 S. Gambino, “Libertà e sicurezza nella recente esperienza nord-americana di contrasto del terrorismo”, en Liber amicorum in onore di Augusto Cerri, Roma, 2016; T.E. Frosini, "Lo Stato di diritto si è fermato a Guantanamo”, en T. Groppi (a cura di), Democrazia e terrorismo, Napoli, 2006; C. Bassu, Terrorismo e costituzionalismo. Percorsi comparati, Torino, 2010.

32 B. Ackerman, ob. cit., 19 ss.
} 
evidente destinada a restaurar el sentido más profundo de pertenencia a una comunidad de Estado, por otra, ha terminado teniendo un impacto problemático en la plenitud misma de las libertades dentro de los sistemas constitucionales individuales y cuestionando el principio mismo de legalidad, con especial atención al derecho penal sustantivo y al derecho procesal, y con ellos a los principios subyacentes de garantías que, a partir de Beccaria, lo caracterizan.

En el equilibrio entre seguridad y libertad, por tanto, la seguridad, al menos en una parte de los sistemas de democracia pluralista, ha asumido un papel (pre)dominante y, en cualquier caso, en una medida mucho más incisiva que la que tuvo lugar antes de los acontecimientos del 11 de septiembre de 2001.

Pero la tendencia a proteger decisivamente la seguridad no surge de repente. Ya se había establecido en los años anteriores a los trágicos acontecimientos a los que se ha hecho referencia tras el empeoramiento de la situación internacional y, en algunos casos -como se observa en Gran Bretaña, España, Francia y Bélgica-, el terrorismo de origen internacional llegó a encajar en una situación ambiental ya gravemente afectada por el terrorismo interno. Más recientemente, este terrorismo se ha considerado capaz de expresarse -con una violencia criminal y una virulencia que han registrado un evidente salto cualitativo en el mismo enfoque del uso de los medios de comunicación y en el enfoque comunicativo con la opinión pública planetaria- invocando su propia legitimidad basada en una estrategia dirigida a la radicalización del islamismo como defensa contra (presuntos) fines depredadores de las potencias occidentales hacia él. Una acción -la segunda- destinada inevitablemente al fracaso cuando se considera la capacidad histórica del Islam de convivir pacíficamente con los pueblos de Europa y Asia y que (al menos en un componente, no se da a conocer su amplitud) ha rechazado indignada la asimilación con el Islam radical y terrorista al que había empujado e instado Al Qaeda, primero, y ahora Abu Bakr al-Baghdadi.

IX. En cuanto a la experiencia italiana en el ámbito de las medidas antiterroristas, una característica común de la legislación son las medidas legislativas (penales y procesales) para agravar los tipos de delitos y las penas relativas (muy a menudo en contraste con el principio de la obligatoriedad de la pena), el aumento de las facultades de investigación de la policía, una compresión significativa de los derechos de los sospechosos y la elevación de duración (ya de por sí elevada) y de la prisión preventiva, una reducción de las garantías judiciales de la tutela judicial efectiva de los acusados con limitación del juez predeterminado, , independiente e imparcial,. Sobre este punto propondremos una revisión de las líneas principales de esta legislación, recordando, al mismo tiempo, las censuras más significativas que el Juez de las leyes ha hecho de ella.

Otro dato recurrente en esta disciplina es el constituido por la tendencia a recurrir a fuentes ordinarias (normalmente decretos leyes, convertidos posteriormente en ley) sin recurrir a proclamaciones formales de "estados de emergencia” y a menudo sin la necesaria cobertura constitucional. La impresión general es que, mientras persista la situación internacional de conflicto o de grave tensión, con sus repercusiones internas, la legislación que limita los derechos se ha hecho crónica, ya que la jurisdicción (tanto ordinaria como constitucional) no es capaz de reconstituir la protección de los derechos y libertades de manera garantista. En este marco, la garantía de los principios del Estado de Derecho acabaría por concentrarse en la coherencia y eficacia de los controles de seguridad encomendados a las fuerzas de seguridad pública, así como en el control del 
comportamiento relativo de la jurisdicción, registrando las representaciones políticas parlamentarias, en tal escenario, una clara sujeción a los requisitos de seguridad impuestos por el Ejecutivo.

En el ámbito de la legislación de lucha contra el terrorismo adoptada en el ordenamiento jurídico italiano, como hemos visto, parece posible captar una tendencia general en la que, por una parte, el ordenamiento jurídico republicano evita recurrir a disposiciones derogatorias o a la suspensión de la Constitución al adoptar disciplinas legislativas que impliquen derechos y libertades, $y$, por otra, se da a entender la puesta en marcha de un sistema (muy amplio y poco sistemático) ${ }^{33}$ de legislación de excepción, que tiene profundas consecuencias para el derecho penal, el derecho procesal y el derecho penitenciario y, por consiguiente, para las garantías constitucionales de las libertades.

Sin embargo, se trata de una "legislación de emergencia" que la Corte Constitucional reconoce como razonable y, por lo tanto, constitucionalmente legítima, ya que se considera proporcional a las necesidades de defensa colectiva contra el peligro de la ofensiva terrorista, así como respetuosa -por su naturaleza de medidas temporales adoptadas- del parámetro constitucional de que se trate en cada momento. Como resume efectivamente el Juez de Leyes en su decisión piloto sobre la materia: "Si debemos admitir que un sistema en el que el terrorismo siembra muerte -también a través del despiadado asesinato de "rehenes" inocentes- y destrucción, conduce a la inseguridad y, por lo tanto, a la muerte, la necesidad de confiar la salvación de la vida y de los bienes a escoltas armados y a policías privados, se encuentra en estado de emergencia, sin embargo, hay que estar de acuerdo en que la emergencia, en su sentido más propio, es ciertamente una condición anómala y grave, pero también esencialmente temporal" (cursiva nuestra). De ello se deduce que legitima, sí, las medidas inusuales, pero que éstas pierden legitimidad, si se prolongan injustificadamente en el tiempo (STC n. 15 de 82) ${ }^{34}$.

X. Desde el primer atentado terrorista (el 12 de diciembre de 1969, en la Banca Nazionale dell'Agricoltura de la Piazza Fontana de Milán), le han seguido una sucesión inimaginable para el País y absolutamente amenazante (también por los objetivos individuales y colectivos elegidos por los terroristas para sus atentados) En Italia, se han producido varios actos terroristas que han causado cientos de muertes entre las fuerzas del orden, el poder judicial y la población civil, revelando así al país la presencia de grupos políticos radicalizados de extrema derecha y extrema izquierda, mortalmente hostiles al Estado democrático.

Respecto al marco de emergencia terrorista, la legislación penal y procesal interviene para contrarrestar el fenómeno (como se acaba de decir, absolutamente nuevo para el País) y lo hace con éxito (relativo) tanto cuando se trata de los resultados del control de constitucionalidad sobre la legislación penal (como se dirá más adelante), como en lo que respecta al mismo éxito de la legislación penal que -incluso en un marco que plantea muchas preocupaciones sobre la constitucionalidad de las disposiciones de emergencia adoptadas y sobre los mismos riesgos de una deriva autoritaria de las instituciones públicas- determina (rectius, ha contribuido a determinar), sin embargo, la derrota de los grupos terroristas inspirados por la radicalización ideológica de la

\footnotetext{
33 A. Pagliaro, “Sulla tutela penale dell'ordine pubblico nella legislazione dell'emergenza”, en Studi in onore di Giacomo Delitala, II, Milano, 1984.

34 G. Neppi Modona, "La giurisprudenza costituzionale italiana in tema di leggi di emergenza contro il terrorismo, la mafia e la criminalità organizzata”, en T. Groppi (a cura di), Democrazia e terrorismo, Napoli, 2006, p. 84 ss.
} 
hostilidad hacia el Estado democrático (que, en la actualidad, parece que puede calificarse de definitiva).

Como se ha observado de manera convincente en muchos lugares, se puede afirmar, también desde el punto de vista del funcionamiento institucional de las políticas criminales seguidas por el legislador ordinario, que "la Constitución parece haber logrado vencer por la fuerza a sus enemigos políticos armados, sin excepciones a sus disposiciones, y posteriormente ha logrado ganar incluso a sus enemigos más peligrosos, nuevos y viejos" 35 .

Para la mitad del siglo siguiente a la aprobación de la Constitución italiana, se puede decir que la República ha ganado el juego contra sus propios enemigos internos ${ }^{36}$. Sin embargo parece que esta legislación es menos eficaz para hacer frente a los nuevos problemas sociales que surgirán con el tiempo, como la emigración masiva, pero sobre todo la aparición de un terrorismo internacional (hasta entonces completamente desconocido para el país, si se exceptúan algunas acciones terroristas limitadas que se remontan a la compleja “cuestión palestina”) y de un terrorismo llevado a cabo por extranjeros o por neófitos italianos de un fundamentalismo religioso de matriz islámica.

No se puede recordar ninguna legislación específica real contra los terroristas extranjeros, desde los años sesenta hasta la legislación que intervino en los primeros años del nuevo milenio (2001-2003) ${ }^{37}$ y sobre todo, con la Ley 155/2005, con la consecuencia de que la lucha contra el terrorismo se lleva a cabo recurriendo a la legislación penal y procesal ordinaria y en el marco de una definición muy poco clara del concepto jurídico de terrorismo y, por lo tanto, no resulta adecuada para apoyar las razones de la acusación en un juicio penal.

XI. Tan brevemente observado, y limitándonos al análisis de la legislación contra la emergencia terrorista implementada en los años 70 y 90 del siglo pasado ${ }^{38}$, puede decirse que bajo el perfil temporal, se desarrolla a partir de una articulación en al menos tres macro fases caracterizadas por los objetivos específicos de la lucha contra el terrorismo que se persiguen de vez en cuando, y teniendo como objeto de dicha legislación cuatro áreas materiales principales: el derecho penal sustantivo, el derecho procesal, la modificación del sistema penitenciario (con el establecimiento de prisiones de máxima seguridad) y, por último, el fortalecimiento de las competencias de la policía (en particular, pero no sólo, con la detención de la policía que, “aunque sea por muy poco tiempo, te hace perder la libertad con relaciones muy lábiles con los delitos y lejos de ser una medida motivada") ${ }^{39}$.

A finales de los años 70, el conjunto de estas medidas legislativas de lucha contra el terrorismo se convirtió en la medida legislativa más relevante y sistemática, el Decreto 625/1979, convertido en la Ley 15/1980, en la que se titulaban Medidas Urgentes para la protección del orden democrático y la seguridad pública.

\footnotetext{
35 P. Bonetti, "Problemi e prospettive costituzionali nella ... cit., p. 96.

36 G. Jakobs, "Derecho penal del ciudadano y derecho penal del enemigo”, in G. Jakobs, M. Cancio Meliá, Derecho penal del enemigo, Madrid, 2003.

37 A. Caligiuri, "Strumenti di contrasto al terrorismo internazionale e tutela dei diritti umani: l'esperienza italiana", en www.academia.edu.

38 A. Baratta, "La politica criminale e il diritto penale della Costituzzione", en S. Canestrari (a cura di), Il diritto penale alla svolta di fine millennio, Torino, 1998, p. 26 ss.

39 R. Minna, Crimini associati, norme penali ... cit., p. 99.
} 
Para comprender mejor el carácter innovador de esa legislación antiterrorista aunque sea en la esencia de su tratamiento- parece oportuno recordar cómo se sitúan esas medidas de lucha contra el terrorismo en una línea de continuidad con la relación y la disciplina de las medidas preventivas (personales y patrimoniales) previstas por el legislador fascista (TULPS/1931), en la plena disponibilidad de las autoridades de seguridad pública a los efectos de su aplicación a los sujetos sobre la base de su peligrosidad meramente presunta, y con independencia de la utilización de cualquier hecho relevante desde el punto de vista penal.

En cuanto a la dudosa conformidad constitucional de tales medidas de prevención, las doctrinas constitucionales y penales se han desacreditado durante mucho tiempo, dividiéndose en directrices articuladas en la lectura de este informe ${ }^{40}$.

Para el Tribunal Constitucional, aunque en el marco de una dirección jurisprudencial no siempre estable, debe reconocerse la plena legitimidad de tales medidas de prevención ${ }^{41}$. El fundamento constitucional relativo proviene del mismo identificado en la necesidad de adecuar dichas medidas a aquellas, aunque notables, limitaciones de ciertos derechos reconocidos por la Constitución que responden “al principio de prevención y seguridad de la sociedad, para lo cual debe garantizarse el desarrollo ordenado y pacífico de las relaciones entre los ciudadanos, así como por el sistema de regulación represiva de los hechos ilícitos, también por un sistema paralelo de medidas preventivas adecuadas contra el peligro de su ocurrencia en el futuro" (STC. n. 27/1959) ${ }^{42}$.

Esta exigencia es "fundamental para todo sistema, aceptado y reconocido por nuestra Constitución”, también en el ámbito del art. 2 Const. italiana que "al afirmar los derechos inviolables del hombre y los deberes imperativos de la solidaridad política, económica y social no puede excluir que los ciudadanos se vean despojados de las restricciones de la esfera jurídica necesarias para la protección del orden social” (STC n. 27/1959, 23/1964 y 75/1966) $)^{43}$.

En la misma línea, en cuanto a la base de las medidas preventivas, el Tribunal asume que "el artículo 25, segundo párrafo, .... incorpora ... en el sistema de medidas de seguridad contra personas socialmente peligrosas. Es cierto que las medidas de seguridad en sentido estricto se aplican después de la comisión de un acto previsto por la ley como delito (artículo 202 del Código Penal), y por lo tanto para una peligrosidad más concreta manifestada, pero como las medidas de seguridad intervienen posteriormente a la expiación de la pena, es decir, cuando el infractor ya ha satisfecho, por el delito cometido, su deuda con la sociedad.... hay que deducir que el objeto de tales medidas sigue siendo siempre el común a todas las medidas de prevención, es decir, la peligrosidad social del sujeto" (Sentencia 27/1959) ${ }^{44}$.

En resumen, lo que caracteriza el procedimiento argumentativo seguido por el Juez de Leyes en materia de medidas de prevención en la lucha contra el terrorismo y el fenómeno mafioso es la finalidad de la garantía prevista en relación con las libertades individuales afectadas por una disciplina legislativa restrictiva en lo que respecta a las

\footnotetext{
40 A. Pace, “Libertà personale (Diritto costituzionale)”, in Enc. dir., XXV, Milano, 1974, p. 287 ss.; L. Elia, Libertà personale e misure di prevenzione, Milano, 1962.

41 G.P. Dolso, “Misure di prevenzione e Costituzione”, in F. Fiorentin (a cura di), Le misure di prevenzione, Torino, 2006.

42 F. Fiorentin, Le misure di prevenzione personali nel Codice antimafia in materia di stupefacenti e nell'ambito di manifestazioni sportive, Milano, 2005, p. 16 ss.

43 F. Fiorentin, Le misure di prevenzione personali nel Codice antimafia ..., cit., p. 16 ss.

44 F. Fiorentin, Le misure di prevenzione personali nel Codice antimafia ..., cit., p. 16 ss.
} 
necesidades de seguridad; dicha finalidad se persigue acentuando las garantías constitucionales otorgadas por la reserva de derecho y, si está prevista, por la reserva de jurisdicción, haciendo emerger en tal equilibrio las exigencias del orden público (democrático), con el fin de conferir legitimidad constitucional a las medidas preventivas previstas a tal efecto.

Por lo que se refiere a la legislación penal sobre emergencias (en particular el terrorismo), un ámbito central, como ya se ha señalado, está ocupado por las medidas preventivas reguladas por la Ley 1423/1956, que son tanto de carácter administrativo (por ejemplo, la advertencia y la repatriación con conocimiento de embarque, que entran en el ámbito de competencia del Questore) como judicial (supervisión especial, posiblemente vinculada a la prohibición o a la obligación de residir, que entran en el ámbito de competencia del Tribunal). El uso de esta disciplina básica y la extensión de las medidas relativas a otras categorías de sujetos sospechosos de pertenecer a asociaciones mafiosas (Art. 1, Ley $\mathrm{N}^{\circ} 565 / 1965$ ) o a grupos criminales subversivos o terroristas (Ley $\mathrm{N}^{\circ}$ $152 / 1975)^{45}$ determinan un enfoque cada vez más significativo de las medidas de prevención al ámbito normativo típico de la represión penal. Por ello, una parte de la doctrina alerta sobre el riesgo de "militarizar las respuestas del Estado contra el terrorismo" ${ }^{46}$, identificando en las medidas de prevención personal "instrumentos aflictivos reales y propios, irrogables a falta de pruebas coherentes con respecto a las causas penales autónomas, distorsionando así los propósitos originales de la actividad de prevención, encaminados a la eliminación de las causas personales y sociales del delito y a la recuperación del sujeto considerado peligroso" ${ }^{47}$.

En cuanto a los perfiles sustanciales de la "nueva” legislación penal, que se encuentra, sobre todo, en la Ley 15/1980 -la medida legislativa más orgánica en la lucha contra el terrorismo que intervino en la fase evolutiva de la legislación que ahora se estudia-, cabe recordar, en particular, la introducción de nuevos tipos penales, severamente sancionadas; entre ellos, la asociación con fines de terrorismo o de subversión del orden democrático (Art. 1 del Código Penal), con un aumento de de la extensión de la pena); el atentado contra la vida o la seguridad de una persona con fines terroristas o la subversión del orden democrático (artículo 2, que introduce un nuevo artículo 280 del Código Penal italiano)o el delito de secuestro con fines terroristas o de subversión del orden democrático, así como la disposición de la duplicación de la pena en presencia de circunstancias agravantes del delito debido a la finalidad terrorista o de subversión del orden democrático ${ }^{48}$. Sobre la base del procedimiento penal, se dispone (art. 6) que la policía puede someter a cualquier persona a una "detención de seguridad” durante 48 horas, dando aviso inmediato al Fiscal General de la República; el Fiscal General de la República puede autorizar a la policía, también por teléfono, a registrar “edificios enteros o bloques de edificios" (art. 9); por último, el art. 14 delega en la policía, en el caso de delitos de terrorismo o de subversión del orden democrático, así como la delincuencia organizada, las investigaciones y los controles en los bancos y las instituciones de crédito. Con el fin de evitar las garantías proporcionadas hasta ahora por el secreto bancario, la policía adquiere un nuevo poder para proceder al rastreo del "dinero sucio” con el fin de identificar a los responsables de los específicos delitos penales.

\footnotetext{
45 V. Grevi, Custodia preventiva e difesa sociale negli itinerari politico-legislativi dell'emergenza, en Pol. dir., 1982, 237 ss.

46 G. Neppi Modona, "La giurisprudenza costituzionale italiana in tema di leggi di emergenza ... cit., p. 94.

47 T.F. Giupponi, "Sicurezza personale, sicurezza collettiva ... cit., par. 3 ss.

48 G. Neppi Modona, "La giurisprudenza costituzionale italiana in tema di leggi di emergenza ... cit., p. 84.
} 
Siguiendo una estrategia que recuerda la conocida estrategia del "puente de plata para el enemigo que huye”, el agravamiento de las penas antes mencionadas va acompañada de una legislación del tipo de recompensa a favor del acusado o del delincuente que, disociándose de los demás acusados, colabora con la justicia (policía y poder judicial) en la recogida de pruebas destinadas a identificar a los culpables. En esta hipótesis, la regla prevé una reducción de la pena (de un tercio a la mitad) para el correum arrepentido que se disocia de los demás. A continuación, se prevé una no punibilidad especial (art. 5) para quienes, de forma voluntaria, tomen medidas para impedir la comisión del delito, aportando pruebas adecuadas para la reconstrucción del acto delictivo y la identificación de otros acusados ${ }^{49}$.

La nueva ley penal sobre la lucha contra el terrorismo otorga a la policía nuevos e importantes poderes, cuya disciplina material ha llevado a más de una sospecha de ilegitimidad constitucional. Estas facultades incluyen la de interrogar a la persona detenida en el contexto de investigaciones de delitos conexos con fines de terrorismo o subversión democrática sin la presencia obligatoria de un abogado y la de realizar escuchas telefónicas (antes de la necesaria autorización de la autoridad judicial). La policía también reconoce otras dos disposiciones importantes: la primera regula la detención policial de las personas sospechosas de haber cometido delitos de terrorismo; la segunda medida legislativa permite a la policía, sin autorización previa del ministerio público, realizar registros domiciliarios en bloques enteros de edificios en los que se sospecha que las personas buscadas han buscado refugio. Por último, cabe mencionar un tercer grupo de medidas que complementan el enfoque que se está adoptando en materia de medidas preventivas y de derecho penal y que están estrechamente relacionadas con el refuerzo de las competencias policiales antes mencionadas y con el aumento progresivo de las penas.

En ambos casos, en el contexto del proceso penal, existe al mismo tiempo una compresión de los derechos de libertad del acusado ${ }^{50}$. Esta limitación se refería en particular al aumento significativo de los plazos máximos de detención preventiva, que condujo a varias sentencias condenatorias de Italia por el Tribunal Europeo de Derechos Humanos, y puede considerarse que fue el origen del debate parlamentario sobre "garantías procesales”, que concluyó con la revisión del artículo 111 de la Constitución.

XII. A continuación es necesario reflexionar sobre la jurisprudencia del Tribunal Constitucional en relación con las medidas previstas en esta legislación de emergencia. El Tribunal reconoce el carácter razonable y, por tanto, la legitimidad de la acción legislativa en materia de lucha contra el terrorismo, al incluir en la legislación de emergencia que se le somete el carácter excepcional (de emergencia) y el carácter esencialmente temporal de las medidas relativas.

Si la emergencia y la temporalidad pueden constituir, para la Corte, razones para justificar la compresión (temporal) de las garantías constitucionales (y como tal la Corte las capta efectivamente), la cuestión del aumento de las condiciones de la detención preventiva no puede sino cuestionar críticamente la doctrina (penal y constitucional), especialmente en vista de la orientación de los garantes esbozada por la Corte en el pasado

\footnotetext{
49 S. Pignatelli, “Criminalità organizzata, diritto premiale e uscita dall’emergenza”, in Quest. Giust., 1985, 1.

50 G. Neppi Modona, “La giurisprudenza costituzionale italiana in tema di leggi di emergenza ... cit., p. 84.
} 
reciente, y materializada en la remoción del Código Penal y el Código de Procedimiento Penal de muchas "incrustaciones autoritarias o mal liberales"51.

Tal enfoque es interrumpido argumentalmente por la Corte con la sentencia 15 de 1982 (significativa y por eso muy citada y comentada), pero la Corte ya había anticipado tal enfoque en 1976 y 1980, respectivamente, con las sentencias n. 88 y n. 1, pero esto no evitará que la doctrina ponga de relieve sus preocupaciones por el nuevo enfoque jurisprudencial, que se considera “anti-garantía”, pero sobre todo, no podrá escapar a la crítica generalizada sobre la instrumentalización del proceso penal para fines de defensa social.

En cuanto a la cuestión de la constitucionalidad planteada ante el Tribunal en relación con las medidas de lucha contra el terrorismo, el Tribunal Constitucional no omite señalar que la cuestión sobre la que debe pronunciarse "provoca una perturbación inmediata y profunda", añadiendo inmediatamente después que "el Parlamento y el Gobierno no sólo tienen el derecho y el poder, sino también el deber preciso e indeclinable de proporcionar, mediante la adopción de una legislación especial de emergencia (STC. 15/1982)” y que, en dicha óptica, la previsión de límites máximos adicionales de prisión preventiva "no puede considerarse irrazonable, por lo que se ha dispuesto en razón de las dificultades objetivas de la investigación sobre los delitos cometidos con fines terroristas.

No obstante, una vez realizada esta evaluación, es necesario que el Tribunal como ya se ha mencionado- establezca ciertos límites a la legitimidad de las nuevas medidas legislativas. Frente a un terrorismo "que siembra la muerte, también a través del despiadado asesinato de 'rehenes' inocentes, y la destrucción (STC 15/1982)”, la situación de emergencia en la que se encuentra el Estado "es ciertamente una condición anómala y grave, pero también esencialmente temporal" (la cursiva es nuestra); de ello se deduce que la emergencia "legitima las medidas inusuales, pero éstas pierden legitimidad, si se prolongan injustificadamente en el tiempo”. Sin embargo, incluso en una situación de emergencia, la prórroga de los períodos de detención no debe ser tal que dé lugar a un "menoscabo sustancial de la garantía".

Es oportuno subrayar, aunque sea de manera lineal, cómo la Corte, al construir su base argumentativa, asume que "el control sobre la razonabilidad de las penas máximas de prisión preventiva debe ser evaluado sobre la base de la relación que ha inducido al Legislador a disponer la prórroga de esas penas (STC 15/1982)”, identificándola, en la continuación de su argumentación, "en las dificultades objetivas que existen para las investigaciones preliminares y de debate” en relación a los casos penales caracterizados por propósitos de terrorismo o subversión de la democracia.

En este sentido, la doctrina penal-procesal autoritativa asume críticamente que el Juez de las Leyes bien podría haberse pronunciado sobre la mera cuestión de constitucionalidad planteada, consistente en la elevación de las penas máximas de prisión preventiva, ya de por sí muy elevadas ante la agravación prevista en la legislación penal sujeta a revisión constitucional.

El malentendido básico que parece anidar en la sentencia -y este es el punto central de la crítica que hace a esta la doctrina- radica en "creer que la prisión preventiva debe ser un medio de búsqueda de pruebas, mientras que debe comenzar sólo cuando ya se hayan adquirido "pruebas suficientes" de la repetición y debe cesar tan pronto como hayan cesado los requisitos de la cautela procesal” 52 , De ello se deduce que "ni el `peligro

\footnotetext{
51 G.D. Pisapia, Legislazione di emergenza e garanzie costituzionali ... cit., p. 187 ss.

52 G.D. Pisapia, Legislazione di emergenza e garanzie costituzionali ... cit., p. 188 ss.
} 
de fuga' ni el 'peligro de contaminación de las pruebas' pueden transformar la prisión preventiva en 'ejecución anticipada de la pena', en abierto contraste con los dictados constitucionales relativos a la 'presunción de inocencia' (art. 27.2 Const. italiana)”53.

Esta posición contrasta con una orientación doctrinal diferente, predominantemente constitucionalista (pero también penalista), que, al reflexionar sobre las posibles repercusiones problemáticas de la legislación de excepción con el carácter democrático general del sistema político-constitucional y en el sistema jurídico en su conjunto a la luz de la ampliación de las penas de prisión preventiva, supone que puede excluirlas, compartiendo plenamente, en este sentido, el razonamiento y las consecuencias argumentativas del Tribunal Constitucional en la sentencia que se examina en la actualidad, e identificando en las disposiciones constitucionales leídas en sus disposiciones combinadas el parámetro de fundamentación de la legitimación de las disposiciones legislativas de la contradicción. Por lo tanto, ninguna violación irreparable de los principios fundamentales del orden constitucional -en opinión de esta orientación doctrinal- se habría determinado sobre la base de lo que confirma la Corte. El agotamiento del período de vigencia de las disposiciones antes mencionadas provoca una pérdida de interés en el debate sobre este punto y, por otra parte, como ya se ha dicho, el Estado ha derrotado a los terroristas, ya que su acción debe centrarse ahora en la solución de las demás emergencias sociales constituidas, sobre todo, por el grave fenómeno de las asociaciones delictivas, la violencia de cuyas acciones no es ciertamente inferior a la producida por los grupos con fines terroristas, y en la fase actual de las medidas más adecuadas para contrastar las formas del nuevo terrorismo basado en la religión, con respecto al cual parece necesario retrotraer el conocimiento de los objetivos terroristas en los que los propios terroristas están implicados como "bombas humanas".

Como conclusión resumida de la reflexión sobre la primera fase de la legislación y de la jurisprudencia constitucional relativa que precedió al atentado terrorista contra las Torres Gemelas de Nueva York, parece oportuno recordar que, junto con la sentencia que se acaba de comentar, sólo una segunda sentencia constitucional ( $\mathrm{N}^{\circ}$ 38/1985), de contenido sustancialmente procedimentalista, aborda directamente la legislación de emergencia contra las agresiones del terrorismo.

En general, la doctrina que lo ha tratado ha revelado cómo el Tribunal Constitucional ha mantenido un perfil muy bajo, sin cuestionarse a sí mismo, como lo han hecho muchas otras jurisdicciones constitucionales occidentales y cómo lo hará el mismo Juez de Leyes después del atentado del 11 de septiembre de 2001 en Nueva York, sobre las estrechas y complejas interrelaciones entre libertad y seguridad, entre democracia y lucha contra el terrorismo ${ }^{54}$.

XIII. En respuesta a los más recientes acontecimientos terroristas ocurridos en diversas partes de Europa, se publicó en el Boletín Oficial $\mathrm{N}^{\circ} 167$, el $1^{\circ}$ de agosto de 2005 , la Ley $N^{0} 155 / 2005$, por la que se convertía el Decreto Legislativo No $144 / 2005$, que contiene medidas urgentes para combatir el terrorismo internacional.

Se trata de una profunda reforma de la legislación de emergencia (cuyo contenido más importante se recordará más adelante) que, por varias razones, rediseña la nueva estrategia penal y procesal para la lucha contra el terrorismo (que, en su dirección

\footnotetext{
53 G.D. Pisapia, Legislazione di emergenza e garanzie costituzionali ... cit., p. 188 ss.

54 T. Groppi (a cura di), Democrazia e terrorismo, Napoli, 2006; A. Di Giovine (a cura di), Democrazie protette e protezione della democrazia, Torino, 2005.
} 
básica, como se verá, será seguida por la posterior legislación antiterrorista, en el año 2015, que actualmente está en vigor, de la $N^{0} 7 / 2015$ - convertida en la Ley No 43/2015).

Además (y más) que sobre la agravación de las penas, como ya se había hecho en la anterior legislación penal (sobre todo en la Ley N ${ }^{\circ}$ 155/2005), la nueva orientación normativa se basa en el agravamiento de las sanciones por los actos y el comportamiento preparatorio de actos terroristas reales y propios, determinando así, respecto de las sanciones penales previstas para el acto terrorista, un retroceso evidente del ámbito material de las actividades de prevención sancionadas por el derecho penal, y así, configurando cada vez más la disciplina penal del País (como ocurre en los demás Países europeos) a las necesidades recibidas en la (cuestionable) teoría de la "ley penal del enemigo”, entendida como ley penal de la mera peligrosidad y no de la culpabilidad.

Se han expresado preguntas y dudas (especialmente por parte del poder judicial penal) sobre la compatibilidad constitucional del nuevo derecho penal y sobre la idoneidad de las nuevas causas penales para resistir con éxito la búsqueda de pruebas en el proceso penal, en particular en lo que respecta a la técnica de sanción seguida, que, como se acaba de señalar, eleva significativamente el umbral de la punibilidad en comparación con el acto delictivo en sentido estricto. A la dificultad de sancionar eficazmente los casos que tienen su origen en el fenómeno terrorista (sobre todo, por la indeterminación del parámetro normativo que constituye la noción de terrorismo y la noción misma de terrorista), se añade ahora la misma indeterminación de la noción de "fines terroristas" a la que se refiere la ley.

Antes de proceder al examen, aunque lineal, de la "nueva" legislación antiterrorista, parece necesario recordar cómo se desarrolla en el ordenamiento jurídico italiano una legislación innovadora de lucha contra el terrorismo (a partir de la tentativa, aunque infructuosa, de una calificación jurídica más precisa de los casos subjetivos y objetivos imputables al terrorismo) sobre la base de las resoluciones adoptadas por el Consejo de Seguridad de las Naciones Unidas ya a raíz de los trágicos atentados del 11 de septiembre, en el marco de la plena voluntad del país de tomar iniciativas preparadas sobre la base de la Carta de las Naciones Unidas para la represión de la financiación de los actos de terrorismo y, en general, de la lucha contra los atentados terroristas. Estas iniciativas incluyen la congelación de posibles recursos financieros destinados a fines terroristas, la lucha económico-financiera contra los sujetos vinculados al terrorismo (en la Resolución se hace referencia expresa a los talibanes), el fomento de la represión penal de las actividades relacionadas con actos terroristas, la mejora de la cooperación judicial y la información administrativa, la lucha contra el blanqueo de capitales y el tráfico de drogas. Todas estas medidas se completan con la explicación de la preocupación de que la condición de refugiado político podría ser un instrumento para la comisión de actos terroristas.

En el espíritu de esta estrategia criminal, incluso antes de la Ley 155/2005, se adoptaron una serie de medidas gubernamentales (posteriormente convertidas en ley) que deben tenerse en cuenta en la respuesta del país a las demandas de la ONU y de la UE en materia de lucha contra el terrorismo internacional. Entre las medidas anteriores a la Ley 155/2005, cabe destacar, por su importancia en la lucha contra el terrorismo, las destinadas a prevenir el blanqueo de capitales (Resolución 13/1973 del Consejo de Seguridad), la Ley sobre la devolución de capitales (Ley 409/2001) con la disposición de la confidencialidad opaca de la devolución de los flujos de capitales exportados al extranjero, la prohibición de la financiación por parte de los talibanes (Decreto 353/2001), la previsión de nuevos casos incriminatorios y del terrorismo internacional (Ley $\mathrm{N}^{\circ}$ 
438/2001), la novedad en el tema de las actividades encubiertas y las interceptaciones preventivas por parte de la policía y los servicios de seguridad ${ }^{55}$.

Volviendo a la Ley $N^{0} 155 / 2005$, que contiene nuevas medidas de lucha contra el terrorismo, especialmente las de carácter internacional, además de las dudas de constitucionalidad, con especial atención al parámetro constituido por el artículo 3 de la Constitución (irracionalidad) y del art. 27.2, Const., debe observarse que el panorama normativo que surge de ella es más bien “complicado y disperso”. Esto conducirá a un intento de síntesis razonada de las líneas más significativas de la política criminal aprobada por el nuevo legislador de emergencia antiterrorista, siguiendo sustancialmente las rúbricas de la articulación legislativa. Haremos la única excepción del (fundamental) art. 15, con el que se insertan en el Código Penal (inmediatamente después del artículo 270 ter) tres nuevas disposiciones destinadas a garantizar una lucha más eficaz contra los grupos terroristas de lo que permiten las disposiciones anteriores del Código Penal (en el texto anterior a la reforma de 2001) en los artículos 270 bis y 270 ter.

Con la integración de tres nuevas disposiciones penales en el Código Penal italiano, se sigue el procedimiento (art. 270 quater) para la disciplina (con sanciones relativas) del "reclutamiento con fines terroristas, incluido el terrorismo internacional", para la nueva disciplina (art. 270 quinquies) para el "adiestramiento en actividades con fines terroristas, incluido el terrorismo internacional”, y para la nueva disciplina (art. 270 sexies) de la "conducta con fines terroristas". Además, con una nueva disposición integradora, el Código Penal prevé el aumento de la mitad de la pena en la hipótesis de que la instigación o apología (a la que se hace referencia en el Código Penal) se refiera a delitos de terrorismo o crímenes de lesa humanidad.

Además de las duras críticas a esta nueva legislación de emergencia que se han mencionado anteriormente, cabe señalar que hay consenso en la doctrina penal (que en el pasado había censurado la mala tipificación de los casos legales en la legislación penal anterior) sobre la nueva disposición del artículo 270 sexies de la ley, relativa a la naturaleza de la "conducta con fines de terrorismo".

Igualmente, mejor definidos que en el pasado están los casos consagrados en el artículo 270 quinquies en relación con los "atentados con artefactos mortales y explosivos”, así como la identificación y sanción de los “alistados” y “entrenados”. El nuevo marco normativo, además, confiere a la Policía la facultad de proceder a la "recogida obligatoria ... de pelo o saliva", sobre la base también de una mera autorización verbal del Primer Ministro, con la imposición de la detención preventiva en la hipótesis de negativa por parte de la persona detenida a ser identificada o de presentación de documentos falsos (Art. 10 y 18 bis Ley 155/2005).

XIV. A partir de la conclusión de este examen esencial de las evoluciones más significativas de la legislación de la emergencia (llegando ahora a la misma modificación de la columna en la legislación antiterrorista más explícita ${ }^{56}$, habrá que recordar ahora los contenidos principales de la ley $n^{\circ}$ 43/2015, de conversión del dl 7/2015 (G.U. n. 91 de 20 de abril de 2015), que contiene medidas urgentes de lucha contra el terrorismo, también de carácter internacional, así como la ampliación de las misiones internacionales de las Fuerzas Armadas y la Policía, iniciativas de cooperación para el

\footnotetext{
55 V. Monetti (“La legislazione antiterrorismo dopo l'11 settembre: il contesto internazionale e l'Italia”, in Questione giustizia, 2002, 1.

56 R. Kostoris, F. Viganò (a cura di), Il nuovo 'pacchetto' antiterrorismo, Torino, 2015.
} 
desarrollo y apoyo a los procesos de reconstrucción y participación en las iniciativas de las Organizaciones Internacionales para la consolidación de los procesos de paz y estabilización, acompañando su llamamiento con una reflexión sobre los equilibrios que la nueva legislación penal establece entre las necesidades del derecho penal sustantivo y las medidas de prevención y los derechos fundamentales de la persona ${ }^{57}$. Una reflexión que resume lo que se ha observado y argumentado anteriormente y concluirá esta contribución.

Continuando con su propia legislación de emergencia antiterrorista y con las directrices legislativas seguidas en otros países directamente afectados por el terrorismo (pero sobre todo en Francia, tras los atentados del 13 de noviembre de 2015 en París), y con el objetivo de aplicar las últimas Resoluciones del Consejo de Seguridad de las Naciones Unidas, la ley regula -con una lógica que no es nada sistémica- una serie de disposiciones innovadoras tanto en el ámbito del derecho penal sustantivo como en el del proceso. Disposiciones más amplias y variadas (que no pueden ser analizadas aquí) caracterizan la nueva legislación contra el terrorismo, definida por una cuidadosa doctrina penal incluso como una "extraña mescolanza”.

Aunque se pueden captar tres perfiles principales en la nueva legislación antiterrorista, el enfoque general de la nueva disciplina es más que heterogéneo, desde la previsión de nuevos contingentes militares para las necesidades de seguridad de la EXPO, a la autorización de nuevos gastos para la vigilancia y seguridad en el Mediterráneo, a la previsión de la detención obligatoria en flagrancia de los contrabandistas de migrantes y de los contrabandistas en las costas del Mediterráneo por los delitos en materia de inmigración clandestina. Estas disposiciones van acompañadas de un endurecimiento de los tipos penales sustantivos y de los procesales, con el fortalecimiento ultra vires de las medidas de prevención en la misma perspectiva ya utilizada por el legislador penal del país, con el fin de imponer sanciones de manera preventiva con respecto a la comisión del hecho de relevancia penal.

Las principales líneas innovadoras de la nueva legislación antiterrorista se refieren, en primer lugar, a la previsión de nuevos casos incriminatorios en materia de terrorismo y al endurecimiento de las sanciones por conductas dirigidas a la realización de actos terroristas, por lo tanto, a la anticipación del umbral de protección en materia de explosivos (con la incriminación de los hechos relativos a los denominados precursores) y, por último, al fortalecimiento de la eficacia de las medidas de prevención (art. 1, párr. 4 de la Ley No. 155/2005), con la previsión de nuevas medidas sancionadoras en el caso de violaciones. El mismo Fiscal Nacional Antimafia también se convierte en Fiscal Nacional Antimafia y Antiterrorismo, asumiendo facultades adicionales en materia de lucha contra el terrorismo.

La proporción necesaria para comprender mejor las medidas innovadoras de lucha contra el terrorismo introducidas por el nuevo "paquete antiterrorista", tras los recientes atentados de París y Bruselas, sigue siendo fundamentalmente la relacionada con la dinámica de la acción terrorista diseñada ex ante para ser mortal hacia el objetivo colectivo al que se dirige el atentado mortal (de nómada con "bombas humanas”). La comprensión de esta proporción es esencial para que la legislación (antigua y nueva) de lucha contra el terrorismo pueda prevenir la comisión del delito y sancionarlo con medidas más estrictas.

57 S. Colaiocco, Le nuove norme antiterrorismo e le libertà della persona: quale equilibrio?, en Archivio penale 2015, fasc. 2, 2. 
En la fase actual, los sistemas penales, frente a algunas prácticas recientes de extremismo fundamentalista islámico (en países europeos y en países asiáticos y africanos), corren el riesgo de perder la mayor parte del potencial sancionador de la legislación penal. Para ser claro, el terrorista (operando de una manera que es al menos aparentemente libre), cuando planifica y organiza la acción terrorista que pretende llevar a cabo -que será mortal para el objetivo que identifica y para sí mismo (prevaleciendo siempre su propia inmolación)- sabe bien que en nada le interesa lo que el Código Penal dispone y sanciona para sancionar tal acción (mortal para sí mismo y para los demás). Para el sistema penal y, en particular, para las autoridades de seguridad pública, el problema se convierte así en el de prever y aplicar las medidas preventivas más adecuadas que impidan que el acto terrorista sea llevado a cabo efectivamente por el terrorista, pero que, al mismo tiempo, no violen las normas mínimas de protección de los principios de garantía penal y, por tanto, de protección de los derechos humanos, en el espíritu de la dignidad humana.

Antes de proceder a una reflexión sobre los perfiles problemáticos de la nueva legislación penal -que, en gran medida, coinciden con los límites ya observados en la anterior legislación de emergencia terrorista- es útil recordar, sin entrar en un análisis detallado de la nueva disciplina, cómo el eje de la nueva estrategia se refiere, en primer lugar, al derecho penal, con la previsión de nuevos casos incriminatorios y circunstanciales en materia de terrorismo. Tomando nota de la especificidad del nuevo terrorismo, que no es el tipo clásico de asociación (ya sancionado por el artículo 270 bis del Código Penal), se prevén nuevas causas penales para combatir las nuevas acciones terroristas, normalmente llevadas a cabo por los denominados "lobos solitarios" 58 .

La nueva legislación penal, desde este punto de vista, prevé y sanciona (art. 270 quater 1) nuevos tipos de delitos destinados a castigar a quienes organizan, financian y propagan viajes para cometer conductas terroristas (con una sanción de prisión de tres a seis años); una nueva disciplina del art. 270 quater del Código Penal italiano con la sanción, aunque menos severa, del sujeto alistado; la sanción, según el modelo francés, de la persona que "se auto adoctrine" en las técnicas de terrorismo; circunstancias agravantes de ese mismo art. Se prevén 270 quinquies si el acto se comete con instrumentos informáticos o telemáticos; asimismo, se establece el castigo accesorio de la pérdida de la patria potestad cuando un menor participa en la comisión de delitos de terrorismo; se prevén sanciones específicas, de carácter penal y administrativo, para sancionar el incumplimiento de las obligaciones en materia de control de la circulación de sustancias (los denominados "precursores de explosivos") que pueden ser utilizados para la construcción de dispositivos con materiales de uso común. En cuanto a las medidas preventivas, la medida de vigilancia especial de seguridad pública puede aplicarse a los “combatientes extranjeros" potenciales; el Questore puede retirar el pasaporte a los sospechosos de terrorismo, en el momento de la propuesta de aplicación de la vigilancia especial de seguridad, con la obligación de permanencia (la medida está sujeta a la validación de la autoridad judicial); las nuevas formas de delincuencia tienen por objeto castigar a quienes contravienen las obligaciones derivadas de la retirada del pasaporte y otras medidas cautelares adoptadas durante el procedimiento de prevención; se prevén penas agravadas para los delitos de apología e incitación al terrorismo cometidos por medios telemáticos; la autoridad judicial puede ordenar a los proveedores

58 F. Viganò, “Minaccia dei 'lupi solitari’ e risposte dell'ordinamento: alla ricerca di un delicato equilibrio tra diritto penale, misure di prevenzione e diritti fondamentali della persona”, en www.penalecontemporaneo.it. 
de servicios de Internet que impidan el acceso a los sitios utilizados para cometer delitos con fines terroristas. En caso de incumplimiento, es el propio Órgano el que ordena la prohibición de acceso a los dominios de Internet pertinentes.

Para ser eficaces, la idoneidad de tales medidas deberá medirse en función de la realidad de su aplicación y, por lo tanto, de la lógica y las necesidades del proceso penal; por lo tanto, cualquier evaluación en esta fase parece prematura. Es sobre la nueva disciplina legislativa, que aporta innovaciones también al código antimafia (Decreto Legislativo 159/2011), que ahora debemos reflexionar porque, probablemente, es sobre la nueva disciplina de aplicación de las medidas de prevención personal, que, como ya hemos observado para la Ley 155/2005, de manera casi inevitable, se concentran las tensiones entre las necesidades de seguridad y los derechos fundamentales y, por lo tanto, pueden plantearse las cuestiones de constitucionalidad de dichas medidas, aunque no se pueden negar las exigencias de las suposiciones de seguridad y de alarma social en la base de la nueva legislación antiterrorista.

Como ya había ocurrido para la legislación de emergencia terrorista de 2005, también en la nueva legislación penal se va a encontrar una línea de fuerte continuidad con las transformaciones en curso del derecho penal que, desde su naturaleza aflictiva y tipificada, se mueve cada vez más hacia una lógica de tipo preventivo, en la que, a estas alturas, "una amplia gama de actividades preparatorias se ven afectadas en relación con la posible comisión de actividades violentas con fines terroristas, con el fin de permitir a los organismos encargados de la aplicación de la ley de estar en condiciones de intervenir mediante medidas cautelares -y, en su caso, medidas previas a la privación de libertadcontra terroristas potenciales, frustrando a su debido tiempo sus planes delictivos, sobre la base de indicios serios de la realidad"59.

El carácter elusivo e impreciso de estas medidas no puede dejar de preocupar a la cultura jurídica más atenta y a la lógica garante que la inspira, planteando interrogantes sobre la compatibilidad con las garantías establecidas en el derecho penal y el derecho constitucional. Esto con especial atención a la vertiente estrictamente penalista, donde es legítimo cuestionar la "tolerabilidad de una anticipación tan masiva de la protección penal, frente a casos que incriminan actos cada vez más lejanos, desde el punto de vista cronológico, de la lesión de los bienes jurídicos que se realiza a través del crimen "fin" del terrorismo... En efecto, es indudable el enorme potencial dañino de los atentados perpetrados por personas que están dispuestas a morir por la causa del islamismo"; Por lo tanto, la legitimidad de la intervención penal preventiva para impedir que se cometan esos ataques a tiempo no debería ser objeto de un debate razonable. El problema, sin embargo, es, por una parte, el del umbral cronológico hasta el cual debe considerarse admisible la retirada de la punibilidad, frente, por ejemplo, a un caso que afecta ahora a cualquier “conducta unívoca finalizada” a la comisión de conductas terroristas, aunque en una hipótesis muy alejada de la realización de tales conductas, llevada a cabo por aquellos que han adquirido, también de forma autónoma, instrucciones para su ejecución ${ }^{60}$; y, por otro lado, el de la congruencia de la respuesta sancionadora, al compás del principio de proporcionalidad entre la medida de la sanción y la gravedad del delito, frente a actos que son sólo preparatorios, y que no dañan todavía ningún bien jurídico

\footnotetext{
59 F. Viganò, “Minaccia dei 'lupi solitari’ e risposte dell'ordinamento ... cit.

60 A. Balsamo, "Decreto antiterrorismo e riforma del sistema delle misure di prevenzione”, en www.penalecontemporaneo.it).
} 
'final' y que también son sancionados, ahora, con la pena mínima de cinco años de prisión” ${ }^{6}$.

La cuestión de los umbrales tolerables para la retirada de garantías debe abordarse en relación con las nuevas medidas preventivas. También en esta hipótesis, el problema reside en el "muy bajo umbral de prueba circunstancial que permite la aplicación de las medidas de prevención, en la ausencia práctica de normas sobre la formación de la prueba en el procedimiento relativo y, en general, en la muy escasa eficacia de las garantías defensivas de que dispone la propuesta, respecto a las que, en general, gozarían -también en la fase cautelar- en el ámbito de un procedimiento penal" ${ }^{62}$. Con el riesgo ya bien subrayado en el pasado por la doctrina (entre la cual, en particular, la misma que recordamos aquí) de que "la adopción de estrategias alternativas al derecho penal -quizás inspiradas por el propósito, querido por gran parte de la doctrina, de evitar la contaminación del derecho penal con mecanismos de pura neutralización de la peligrosidad individual- se resuelva, de hecho, en una pérdida estricta en términos de protección de los derechos fundamentales del receptor de las 'nuevas' medidas coercitivas, extremadamente aflictivas aunque formalmente calificadas como 'no penales" $" 63$.

A modo de conclusión de la reflexión sobre el trabajo de reconstrucción de la legislación de la emergencia y los equilibrios operados por la jurisprudencia constitucional en materia de derechos fundamentales y seguridad, así, las conclusiones del citado autor son también las nuestras cuando afirma "Ciertamente, el sistema tiene el derecho, y el deber, de defenderse, ante la perspectiva de atentados catastróficos, como desde los últimos franceses del pasado 13 de noviembre. Pero sobre cómo cumplir esta tarea esencial, sin sacrificar el patrimonio de los derechos humanos que es, después de todo, la fuente más auténtica de orgullo de nuestras sociedades occidentales, habrá que pensar mucho más" 64 .

En resumen, los problemas se plantean y en su dura realidad parecen bastante claros. Las soluciones que han sido y serán puestas en práctica por los legisladores y gobiernos occidentales (y por los gobiernos italianos en lo que a nosotros respecta) deben, sin embargo, asumir que los retos del terrorismo deben afrontarse sin ser capaces de oscurecer las normas y garantías del Estado de Derecho constitucional. Derrotar el terrorismo procediendo “con las manos atadas a la espalda” (como Barak, Presidente del Tribunal Constitucional de Israel, señaló efectivamente en 1999, en un difícil y no exento de problemas del sionismo de la época) le dará al resultado del desafío en curso el valor añadido de haberlo hecho sin traicionar los valores y principios que garantizan los altos valores de la cultura democrática occidental, desde Beccaria hasta las cartas constitucionales contemporáneas. Hoy en día, se supone que estos valores-principios son bienes esenciales. Equilibrarlas es el verdadero reto que la cultura occidental debe aprender para gobernar y a hacerlo a pesar de los trágicos ataques del fanatismo religioso y el fundamentalismo que están ensangrentando los distritos de Europa y del mundo entero.

\footnotetext{
61 F. Viganò, “Minaccia dei 'lupi solitari’ e risposte dell'ordinamento ... cit.

62 F. Viganò, “Minaccia dei ‘lupi solitari’ e risposte dell'ordinamento ... cit.

63 F. Viganò, “Minaccia dei 'lupi solitari’ e risposte dell'ordinamento ... cit.

64 F. Viganò, “Minaccia dei 'lupi solitari’ e risposte dell'ordinamento ... cit.
} 


\section{BI BLI OGRAFÍ A}

A. BALSAMO, "Decreto antiterrorismo e riforma del sistema delle misure di prevenzione", en www.penalecontemporaneo.it)

A. BARAK, “The Supreme Court and the Problem of Terrorism”, in Judgements of the Israel Supreme Court; Fighting Terrorism within the Law, Gerusalemme, Institute for Legislative Research and Comparative Law, 2005

A. BARATTA, "La politica criminale e il diritto penale della Costituzzione", en S. Canestrari (a cura di), Il diritto penale alla svolta di fine millennio, Torino, 1998

A. CALIGIURI, "Strumenti di contrasto al terrorismo internazionale e tutela dei diritti umani: l'esperienza italiana”, en www.academia.edu

A. Di Giovine (a cura di), Democrazie protette e protezione della democrazia, Torino, 2005

A. PACE, “Libertà personale (Diritto costituzionale)”, in Enc. dir., XXV, Milano, 1974

A. PAGLIARO, "Sulla tutela penale dell'ordine pubblico nella legislazione dell'emergenza”, en Studi in onore di Giacomo Delitala, II, Milano, 1984

B. ACKERMAN, La Costituzione di emergenza. Come salvaguardare libertà e diritti civili di fronte al pericolo del terorrismo, Roma, 2005

C. BASSU, Terrorismo e costituzionalismo. Percorsi comparati, Torino, 2010

C. VIGILANTI, "I diritti dei terroristi. (Il caso Trabelsi: un difficile equilibrio fra esigenze di pubblica sicurezza e garanzie dei diritti fondamentali)", en www.forumcostituzionale, 2010

F. FIORENTIN, Le misure di prevenzione personali nel Codice antimafia in materia di stupefacenti e nell'ambito di manifestazioni sportive, Milano, 2005

F. PIZZETTI, "Lotta al terrorismo e tutela della privacy”, in AA.VV., Lotta al terrorismo e tutela dei diritti costituzionali, Torino, 2009

F. VIGANÒ, “Minaccia dei 'lupi solitari' e risposte dell'ordinamento: alla ricerca di un delicato equilibrio tra diritto penale, misure di prevenzione e diritti fondamentali della persona", en www.penalecontemporaneo.it

G. DE VERGOTTINI, "La difficile convivenza tra libertà e sicurezza: la risposta delle democrazie al terrorismo. Gli ordinamenti occidentali”, en AA.VV. (A.I.C.), Annuario 2003. Libertà e sicurezza nelle democrazie contemporanee, Padova, 2003;

G. JAKOBS, "Derecho penal del ciudadano y derecho penal del enemigo", en G. Jakobs, M. Cancio Meliá, Derecho penal del enemigo, Madrid, 2003

G. NEPPI MODONA, "La giurisprudenza costituzionale italiana in tema di leggi di emergenza contro il terrorismo, la mafia e la criminalità organizzata”, en T. Groppi (a cura di), Democrazia e terrorismo, Napoli, 2006

G. PECES-BARBA, Teoria dei diritti fondamentali, Milano, 1993

G.P. DOLSO, "Misure di prevenzione e Costituzione”, en F. Fiorentin (a cura di), Le misure di prevenzione, Torino, 2006

J. LOZANO MIRALLES, "Seguridad Común e Integración Europea en la lucha contra el Terrorismo en la Unión Europea”, en Federalismi.it, n. 1/2019

L. ELIA, Libertà personale e misure di prevenzione, Milano, 1962

L. STORTONI, "Diritti dell'uomo ed emergenza: (l'eredità de) gli anni di piombo”, en Critica del diritto, 1997, 1

L. WURTZ, “Obsessions sécuritaires”, en Le Monde diplomatique, octubre 2003. 
M. PATRONO, I diritti dell'uomo nel paese d'Europa. Conquiste e nuove minacce nel passaggio da un millennio all'altro, Padova, 2000

M. RUOTOLO, “La sicurezza nel gioco del bilanciamento”, en G. Cocco (a cura di), I diversi volti della sicurezza, Milano, 2012

M. VOLPI, La democrazia autoritaria, Bologna, 1979

P. BONETTI, “Terorrismo e stranieri nel diritto italiano. Disciplina legislativa e profili costituzionali”, en Diritto, immigrazione e cittadinanza, 2005

P. CERI, La società vulnerabile. Quale sicurezza, quale libertà, Roma-Bari, 2003

R. KOSTORIS, F. Viganò (a cura di), Il nuovo 'pacchetto' antiterrorismo, Torino, 2015

S. COLAIOCCO, "Le nuove norme antiterrorismo e le libertà della persona: quale equilibrio?”, en Archivio penale 2015, fasc. 2, 2

S. GAMBINO, "Libertà e sicurezza nella recente esperienza nord-americana di contrasto del terrorismo", en Liber amicorum in onore di Augusto Cerri, Roma, 2016

S. GAMBINO, A. Scerbo, "Diritti fondamentali ed emergenza nel costituzionalismo contemporaneo. Un’analisi comparata”, en Rivista di Diritto Pubblico Comparato ed Europeo, n. 4/2009

S. PIGNATELLI, “Criminalità organizzata, diritto premiale e uscita dall'emergenza”, in Quest. Giust., 1985, 1

T. GROPPI (a cura di), Democrazia e terrorismo, Napoli, 2006

T.E. FROSINI, "Il diritto costituzionale alla sicurezza", in www.forumdiquadernicostituzionali.it

T.E. FROSINI, "Lo Stato di diritto si è fermato a Guantanamo”, en T. Groppi (a cura di), Democrazia e terrorismo, Napoli, 2006

T.E. FROSINI, C. Bassu, "La libertà personale nell'emergenza costituzionale”, en A. Di Giovine (cur.), Democrazie protette e protezione della democrazia, Torino, Giappichelli, 2005

V. GREVI, "Custodia preventiva e difesa sociale negli itinerari politico-legislativi dell’emergenza”, en Pol. dir., 1982, 237 ss.

V. MONETTI "La legislazione antiterrorismo dopo l'11 settembre: il contesto internazionale e l’Italia”, en Questione giustizia, 2002, 1. 